\title{
Material Advantage Member Receives Georgia Tech Honors; Discover Member Benefits from TMS; Welcome New Members \\ themagazine
}
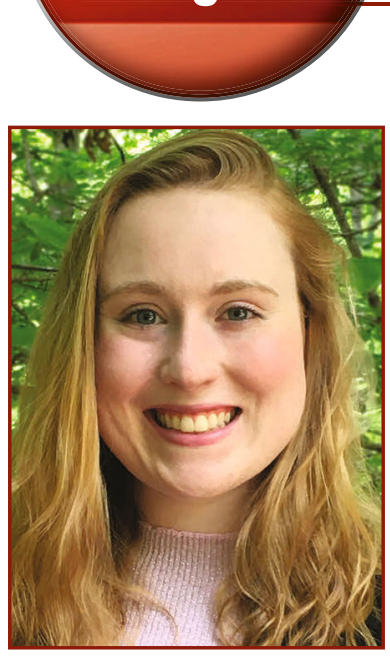

Lily Turaski

\section{Lily Tursaski Awarded Engineering Cup from Georgia Tech}

Material Advantage member Lily Turaski, a senior at the Georgia Institute of Technology (Georgia Tech), was awarded the Davidson Family Tau Beta Pi Senior Engineering Cup, the highest honor bestowed by Georgia Tech's College of Engineering. The Cup, which recognizes academic excellence, leadership, and service, is supported by the family of Narl Davidson, past associate dean at the College of Engineering, and Tau Beta $\mathrm{Pi}$, a national honor society for engineers.

At Georgia Tech, Turaski is a Stamps President's Scholar and received the 2019 Goldwater Scholarship. She created two student groups at Georgia Tech, Women in
Materials Science and Engineering (MSE) and MSE Peer Partners Organization, and further participates in various outreach programs and activities to get local $\mathrm{K}-12$ students interested in science, technology, engineering, and math (STEM). Upon graduating, Turaski will begin her Ph.D. in materials science engineering at Stanford University, with funding by a fellowship from the National Science Foundation.

Turaski has been a member of Material Advantage since 2017, recently serving as her chapter's vice president. In 2021, she received the TMS Functional Materials Division Gilbert Chin Scholarship as well as first place in the TMS Best Paper Contest - Undergraduate.

\section{Just for Students}

If you are about to graduate or have graduated in the last year, take advantage of the TMS Recent Graduate membership program. Designed to make TMS membership affordable during the early years of your career, one year of professional membership after graduation is free.

For the second and third years after graduation, the cost of membership is just $\$ 60$, half the cost of professional member dues. To apply, fill out the recent graduate membership form found on the Recent Graduate link at www.tms.org /Membership. Forms can be returned to members@tms.org.

\section{Explore Your Member Benefits}

Your TMS membership is a great way to stay connected-with your colleagues around the world, with the latest developments in your field, and with topics of current interest to your community. Log in to members.tms.org and spend a few minutes testing out a member benefit you have not tried before, such as:

- Membership Directory: There are plenty of TMS members you've never met - find ones who share your technical interest and introduce yourself.

- Webinar Library: Sign up for a live, upcoming webinar or view past offerings at your leisure - all free to members.
- Journals: As a TMS member, you have electronic access to more than 20 technical journals from TMS and our publishing partner Springer. Log in to start reading.

- Online Libraries: Explore more than 4,500 technical articles and documents through the TMS Member Library, the AIME Digital Library, and the Superalloys Conference series archive.

Members can access any of these resources by logging in to the Access Member Benefits section of the TMS website at members.tms.org. While there, remember to update your member profile with any changes to contact information or technical interests.

\section{member news}

Share the good news about your professional accomplishments! Contact Kaitlin Calva, JOM Magazine Managing Editor, at kcalva@tms.org. Please note that only news submitted by current TMS members will be considered. 


\section{Make a Commitment to Safety in June}

Did you know that June is National Safety Month, as dedicated by the U.S. National Safety Council? Make a plan to attend the first Congress on Safety in Engineering and Industry (Safety Congress 2021) in honor of this month-long awareness event. Safety Congress 2021 is scheduled for November 1-3, in Fort Worth, Texas. Advance registration rates are available through September 20.

Geared toward leaders, managers, and safety professionals seeking to expand their skill sets and gain cutting-edge knowledge, attendees will learn best practices through dozens of experts, five plenary sessions, and 18 interactive breakout sessions. The program will cover areas such as: Operational, Process, and Project Safety; Safety Management; System Design and Implementation; Effective Use of Data Metrics; and more.

"I believe that a challenge for most industries and companies may be how to effectively learn from the past," said Roland Moreau, program chair for Safety Congress 2021, in a January 2020
$J O M$ preview article about the meeting. "I am hoping that this event will allow participants to equally share successes and challenges with the objective of everyone collaborating and partnering to make the work environment safer, including at the university level."

Additionally, two professional development offerings are planned for October 31-Process Safety in Engineering and Industry Course and Certified Mine Safety Professional (CMSP) Examination. Learn more about these programs and register today at www.safetycongress.org.

Safety Congress 2021 is the first combined effort of eight professional societies and the National Academies to collaborate on safety successes and challenges. The United Engineering Foundation, the McElhattan Foundation, and the National Academies' Gulf Research Program have also provided support for the event.

\section{TMS Welcomes New Members}

\section{The TMS Board of Directors approved professional membership for the following individuals at its March 2021 meeting. Please join us in congratulating and welcoming them to all the privileges and benefits of TMS membership.}

Abu-Zahra, Nidal H.; University of WisconsinMilwaukee, United States

Adams, Thomas; Naval Surface Warfare Center, United States

Ajantiwalay, Tanvi; United States

Alarifi, Ibrahim M.; Majmaah University, Saudi Arabia

Ali, Yahia; University of Queensland, Australia

Bair, Jacob; Oklahoma State University, United States

Balachandran, Anusha; United States
Balazsi, Katalin; Hungarian Academy of Sciences, Hungary

Balila, Nagamani Jaya; Max Planck Institut für Eisenforschung, India

Bao, Sarina; SINTEF Materials \& Chemistry, Norway

Bartles, Dean L.; Manufacturing Technology Deployment Group, United States

Bates, Jeffrey S.; University of Utah, United States

Belen-Cordero, Daphne S.; Naval Nuclear Laboratory, United States

Bolen, Janice; Hatch Ltd., Canada
Bruns, Edward; United States

Burciaga-Diaz, Oswaldo; Instituto Tecnológico de Saltillo, Mexico

Burke, Michael; Electric Power Research Institute, United States

Campbell, Jeff; Materion, United States

Carden, Sean; Vesuvius, United Kingdom

Chava, Venkata S.N.; United States

Chen, Jiang; Australian National University, Australia

Choi, Jungwoo; Samsung Electronics, South Korea

Choi, Sungyeol; KAIST, South Korea
Colligan, Grant T.; United States

Coudert, Lucie; Universite du Quebec en AbitibiTemiscamingue, Canada

Dandekar, Yogesh; Cummins College of Engineering for Women Nagpur, India

Davis, Robert F.; Carnegie Mellon University, United States

De Luca, Anthony; EMPA, Switzerland

Dechent, Matthias; Trimet Aluminium SE, Germany

Dietrich, Rob; United States 


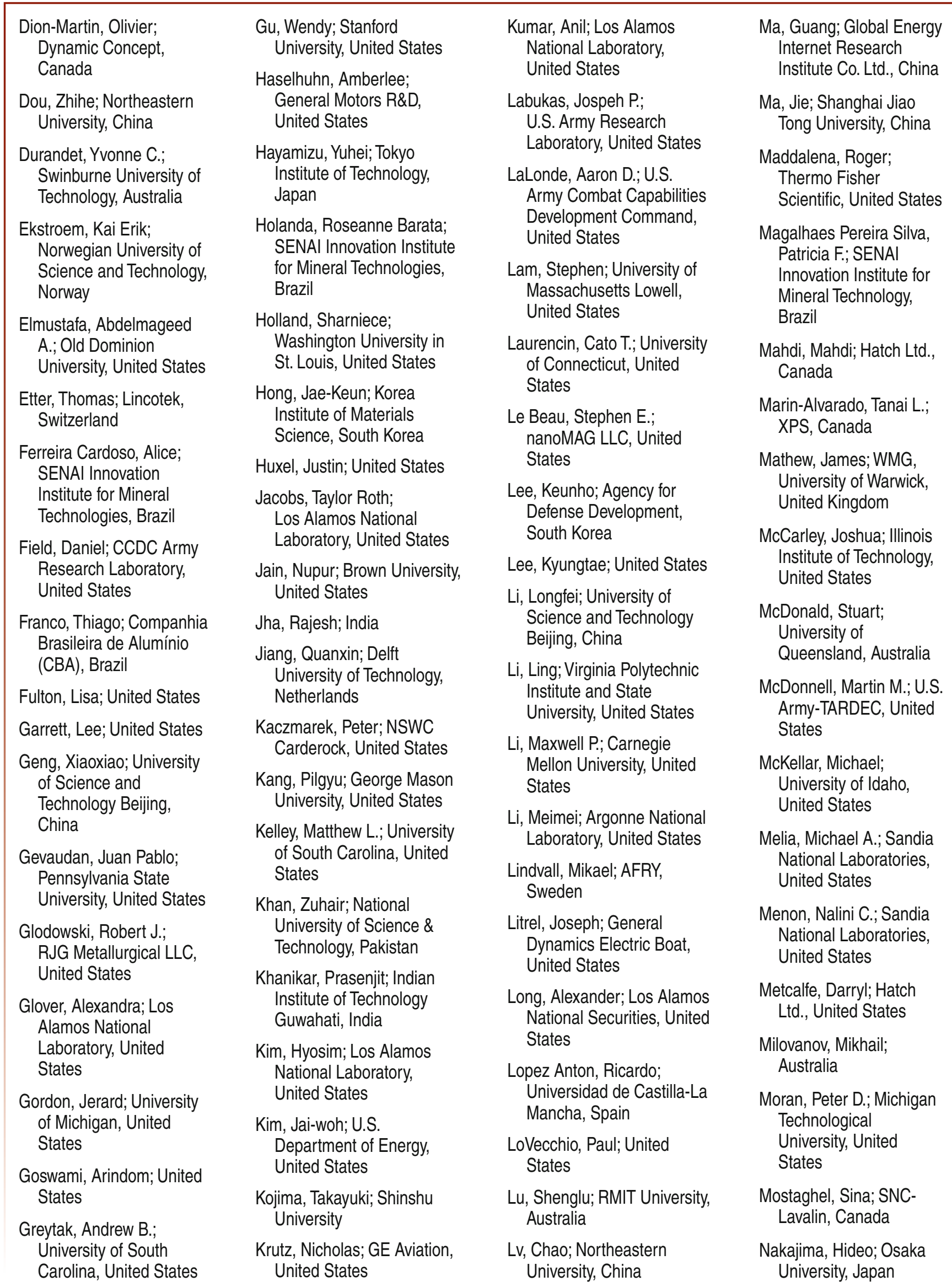




$$
\begin{aligned}
& \text { Nell, Johannes; Tronox, } \\
& \text { United States } \\
& \text { Nienaber, Maria; } \\
& \text { Helmholtz-Zentrum } \\
& \text { Geesthacht, Germany }
\end{aligned}
$$

Niu, Xinrui; City University of Hong Kong, Hong Kong

Nolet, Isabelle; Hatch Ltd., South Africa

Nomoto, Akiyoshi; Central Research Institute of Electric Power Industry, Japan

Nowell, Matthew M.; TexSem Laboratories Inc., United States

Okur, Serdal; Structured Materials Industries Inc., United States

Ouyang, Bin; United States

Pambianchi, Michael Scott; Industrion, United States

Panetta, Paul; Applied Research Associates, United States

Pascucci, Marina R.; CeraNova Corporation, United States

Patki, Priyam; University of Michigan, United States

Peters, David; United States

Phanikumar, Gandham; Indian Institute of Technology Madras, India

Pikul, James H.; University of Pennsylvania, United States

Pol, Vilas; Purdue University, United States

Poulin, Eric; Laval University, Canada
Remy, Guillaume; University of Warwick, United Kingdom

Rezaei, Seyed Emad; University of Virginia, United States

Rheinheimer, Wolfgang; Julich Research Center, Germany

Rojas, Jessika V.; Virginia Commonwealth University, United States

Russell, Richard W.; NASA Kennedy Space Center, United States

Sagapuram, Dinakar; Texas A\&M University, United States

Salloum, Maher; Sandia National Laboratories, United States

Sanders, John W.; California State University Fullerton, United States

Sapochak, Linda S.; National Science Foundation, United States

Sayer, Aaron B.; Materion Brush Beryllium and Composites, United States

Schultz, Bradley M.; TE Connectivity, United States

Secord, Mick; Polyonics Inc., United States

Serafeim, Alexandros; RWTH, Germany

Shigeyama, Haruhisa; Central Research Institute of Electric Power Industry, Japan

Singh, Sudhanshu Shekhar; Indian Institute of Technology Kanpur, India

Singh Gaur, Raj Pal; SH Chemicals, United States

Slater, J.E.; United States
Smith, Timothy; NASA Glenn Research Center, United States

So, Lily Lai Chi; Hatch Ltd., Canada

Sokalski, Vincent M.; Carnegie Mellon University, United States

Solis-Ramos, Euripides; United States

Sundqvist, Olle; Sandvik Materials Technology, Sweden

Taller, Stephen; United States

Tompa, Gary S.; Structured Materials Industries Inc., United States

Ukeje, Chukwudike Chukwunenye; Nigeria

Ullah, Asad; Karakoram International University, Pakistan

Uno, Masayoshi; University of Fukui, Japan

Vilaca do Carmo, Andre Luiz; SENAI Innovation Institute for Mineral Technologies, Brazil

Vubangsi, Mercel; The University of Bamenda, Cameroon

Wakabayashi, Hideki; Japan

Walters, Carey; Delft University of Technology, Netherlands

Wang, Shuai; Southern University of Science and Technology, China

Wang, Hao; University of Science and Technology Beijing, China

Westraadt, Johan; Nelson Mandela University, South Africa

Wiesner, Valerie L.; NASA Langley Research Center, United States
Williams, Mark A.; University of Warwick, United Kingdom

Wilson, Paul; The Boeing Company, United States

Wroblewski, Krzysztof P.; Wroblewski Consulting, United States

Xia, Zhenhai; University of North Texas, United States

Xiang, Song; Guizhou University, China

Xie, Yi; Purdue University, United States

Xin, Hongliang; Virginia Polytechnic Institute and State University, United States

Xue, Weihua; Liaoning Technical University, China

Yacoubian, Araz; LER Technologies Inc.; United States

Yadav, Shwetabh; Texas A\&M University, United States

Yang, Junjie; New Jersey Institute of Technology, United States

Yang, Shu; University of Pennsylvania, United States

Yoo, Yung Suk; University of Michigan, United States

Yu, Dawei; Central South University, China

Zell, Elizabeth; Idaho National Laboratory, United States

Zhang, Jianjing; Capitech Venture Capital Co. Ltd., China

Zhao, Qiuyue; Northeast University, China 